\title{
DEVELOPMENT OF AN INTERACTIVE EDUCATIONAL ENVIRONMENT FOR THE DIGITAL TRANSFORMATION OF THE SCHOOL
}

\author{
Natalia A. Biryukova ${ }^{1 *}$, Andrey A. Potapov ${ }^{2,}$ Tatiana A. Volkova ${ }^{3}$ \\ Tatiana V. Kornienko ${ }^{4}$ \\ ${ }^{1}$ Assoc. Prof., Faculty of General and Vocational Education, Mari State University, RUSSIA, \\ biryukova316@gmail.com \\ ${ }^{2}$ Gymnasium \#24 named after I.A. Krylov, St. Petersburg, RUSSIA, \\ andreas1980@bk.ru \\ ${ }^{3}$ Assoc. Prof., Faculty of General and Vocational Education, Mari State University, RUSSIA \\ tat451706@yandex.ru \\ ${ }^{4}$ Gymnasium \#24 named after I.A. Krylov, St. Petersburg, RUSSIA \\ t_v_kornienko@mail.ru \\ ${ }^{*}$ Corresponding Author
}

\begin{abstract}
The current situation of the development of the digital economy and the information society poses a new challenge for schools to change approaches to the educational process. The world community recognizes education as the main factor of development. It was stated in the "2030 Agenda for Sustainable Development", adopted by the UN in 2015. One of the directions of the sustainable development in education is the digital transformation of schools. The digital transformation of a school means updating the planned educational results, content, methods, forms of assessing the results achieved by schoolchildren in the digital environment. The authors analyze the necessary changes in the organization of educational spaces of the school; the introduction of teaching methods supported by digital technologies based on augmented reality. Augmented reality refers to the imposition of digital objects (text, graphics, audio, video, hypertext) on objects of the real world to supplement them with information. The aim of the study was to identify the conditions for the effective use of augmented reality for transforming the school space into an interactive gaming educational environment. The authors argue that the use of digital technologies to ensure the sustainable development of the school will be effective if augmented reality markers are integrated into the educational space of the school. The study was based on several schools in St. Petersburg; its sample included 450 schoolchildren and 70 teachers and administration. The data obtained during the experiment confirmed the hypothesis: the integration of augmented reality markers into various school spaces contributes to the development of special tools to improve the quality of educational results.
\end{abstract}

Keywords: digital transformation of education, augmented reality, educational environment, sustainable development

\section{INTRODUCTION}

Sustainable development as an innovative strategy is an integral part of the modernization of modern education. This concept was first formulated in a Report of the International Commission on Environment 
and Development in 1987. Sustainable development refers to development that meets the needs of the present but does not compromise the ability of future generations to meet their own needs. Education is the main component that makes it possible to achieve the basic goals of sustainable development of society. High-quality education helps to eliminate poverty, to reduce social inequality, achieve gender equality, and expands opportunities for people to live a healthier and more stable life (Matveeva,2017).

One of the problems of the modern Russian school is the problem of the digital divide. To solve it, it is necessary to develop a variety of computer technologies and form people's digital competence. In the modern digital world, it is digital competence that becomes a necessary condition for full-fledged existence in the information society, professional self-realization, economic prosperity of society and effective social interaction of its members. An important condition for bridging the digital divide is the use of new educational technologies that allow effective and safe use of digital technologies in various spheres of life. Mediatization and gamification of education help to increase the motivation and interest of modern schoolchildren in learning. According to world experts, the market of educational games will be maximally integrated into the educational environment in the coming years (Kornienko, Potapov, 2020).

Augmented reality technology is a promising educational technology that increases the interest and motivation of schoolchildren, as well as contributes to bridging the digital divide. Augmented reality refers to the imposition of digital objects (text, graphics, audio, video, hypertext) on objects of the real world in order to supplement them with information. Augmented reality is a hidden digital content that uses special markers to display it. This marker can be a graphic image or a real object. The software recognizes this marker, and an augmented reality object is displayed on the screen of the mobile device instead (Biryukova, Petrova, 2020).

\section{MATERIALS AND METHODS}

The aim of the study is to identify the conditions for the effective use of augmented reality technology for the transformation of school space into an interactive gaming educational environment. The hypothesis of the study is that the use of digital technologies to ensure the sustainable development of schools will be effective if augmented reality markers are integrated into the educational space.

An electronic survey was conducted among 70 teachers of the I. A. Krylov Gymnasium \#24 and School \#17 (St. Petersburg, Russia) on the existing types of digital gaps. The instrumental and technological gap was noted by $3 \%$ of teachers, methodological $-37 \%$ and semantic $-60 \%$ of respondents. Thus it became clear that the educational organizations on the basis of which the study is conducted have resolved the issue of providing technological tools (there is practically no instrumental-technological gap). The types of digital gaps associated with the teaching methodology (37\% of teachers indicated its presence) and the ability to stimulate active subject learning remain relevant $(60 \%$ of respondents noted the presence of this type of digital gap). Also, teachers of the studied educational organizations answered that the share of project and research works of students, in which interactive services, infographics and other information visualization tools were used, was 15\%. The students themselves (a total of 450 people) in the course of oral and electronic surveys on the level of their educational motivation showed that the low level is noted in $10 \%$, the average - in $64 \%$, the high - in $26 \%$.

In our research, we transform the existing educational environment into an interactive educational space based on augmented reality in two key areas: the organization of transformable spaces and the aggregation of content. Analysis of strategies for implementing the organization of transformable school spaces showed the following. The first strategy is to create an educational space for the implementation of media education. In this context, the study room is equipped with mobile furniture, which is easily arranged depending on the purpose of the work - for theoretical classes, working in groups, at computers, and so on. Also in the room there is the necessary computer equipment with licensed software, office equipment, mobile photo and video studios (Potapov, 2019).

The next strategy for organizing transformable spaces is the creation of interactive zones in the recreation areas and foyers of the school. For example, interactive 3D coloring pages with augmented reality (for example, "Quiver") allow you to take your free time with digital creativity and hold an interactive game with children. The use of augmented reality technology also makes it possible to significantly modernize the segment of the information space for parents (Biryukova, Domracheva, 2018). Virtual expansion of stands becomes possible with the help of augmented reality markers, the simplest example of which is QR codes. This method allows multiplying the amount of information presented at the stands and addressed to a specific target audience.

The use of augmented reality markers in the organization of school bookcrossing space allows the reader to 
learn the opinions of peers and teachers about the book to read. Separately, we will highlight the possibility of using augmented reality applications for recreation in a playful way. For example, a printed and attached to the wall marker of a basketball simulator becomes a basketball basket, and the space next to it becomes a place for a virtual competition and real motor development. The basis of this space for the placement of an art gallery is made up of objects of artistic creativity, which are compared by means of augmented reality with digital objects. Each work is marked with a QR code associated with the author's digital portfolio or additional audio-visual information about the object. The next direction of transforming school space into an interactive educational environment based on augmented reality is content aggregation. Content aggregation refers to the centralization of electronic content and the integration of digital resources created in augmented reality technology.

There are two examples of the implementation of this direction. The first is the construction of the "STOIC" space on the basis of the training room. The name "STOIK" is an abbreviation of the name of the developer company (LLC "Modern Technologies in Education and Culture", Moscow, Russia). Using a nettop that distributes wi-fi and on which the hardware and software complex "STOIC-Content" is installed [7], allows you to connect additional digital objects to a real object and provides teachers with the opportunity to develop thematic projects, build intersubject connections, organize multi-scenario educational events and individual educational trajectories. When using this tool, students use mobile devices with an internal network without access to the Internet. Students have the ability to access only those objects that the teacher has chosen. The tool is effectively used in the organization of thematic interdisciplinary expositions, educational quests, in the work of the school library, museum pedagogy, in the organization of surveys for the purpose of reflection of the audience. The second example of content aggregation is the publication of a printed publication. Most of the augmented reality applications we use use printed markers to navigate to a digital object. This fact allows you to combine content created in different applications, based on the unity of content. In this case, a print edition dedicated to a specific topic is generated. This printed publication can be: a school newspaper; methodological development of the lesson; the program of an educational event and others.

\section{RESULTS}

In the course of the study, the authors carried out the transformation of school space into an interactive gaming educational environment based on the use of augmented reality in two key areas and using various strategies. After the implementation of this transformation of the space, repeated interviews and interviews were conducted with teachers and students of the I.A. Krylov Gymnasium \#24 and School \#17 (St. Petersburg).

The results among teachers showed that the instrumental-technological type of digital divide was not shown by any person. $27 \%(-10 \%)$ consider the methodological gap to be their deficit, and $45 \%(-15 \%)$ consider the semantic gap to be a professional deficit. Thus, $28 \%$ of teachers began to believe that they have overcome the digital divide. Of course, we believe that to confirm this result, it is necessary to conduct additional diagnostics. At the same time, according to teachers, the number of project and research works performed by students, which use elements of augmented reality, interactive services, texts of a new nature and other means of information visualization, has increased 3 times (45\% vs. $15 \%$ ).

The reorganization of the traditional school spaces into an interactive educational environment with the help of augmented reality has had a positive impact on increasing the level of educational motivation of students. The average level was observed in $55 \%$ of respondents, and high - in $40 \%$. These results are confirmed by the overall positive dynamics of their educational results and an increase in the activity of students in terms of participation in educational and socially significant activities.

\section{CONCLUSION}

The examples of mobile applications based on augmented reality technology considered in the article meet the following basic principles of selection for use in practice: educational potential, that is, the possibility of using it to achieve educational goals, and not just the "wow effect"; free (shareware) installation and use; performance on mobile devices with major operating systems (primarily Android and iOS). The promotion of educational technologies that are massively accessible in terms of devices used and financial costs is one of the main conditions for bridging the digital divide and contributes to the implementation of the concept of sustainable development in the field of education. 


\section{REFERENCE LIST}

Biryukova N.A., Petrova T.N., Potapov A.A. et al. (2020). Augmented Reality in the Development of Technological Competence of Primary Schoolchildren. Abstracts \& Proceedings of INTCESS 2020 7th International Conference on Education and Social Sciences. Dubai, UAE.

Biryukova N.A., Domracheva S.A., Sinagatullin I.M. (2018). The andragogic approach to cooperation of future teachers with junior schoolchildren's parents. Proceedings of INTCESS 2018. Istanbul, Turkey.

Kornienko T.V., Potapov, A.A., Petrova, T.N. (2020) Profile training of schoolchildren by means of media education. St. Petersburg.

Matveeva T.E. (2017) Idea and factors of sustainable development in the economy and education. Novosibirsk, 2017.

Potapov, A.A. (2019) Augmented reality as a tool for creating an educational SMART space for children 6-10 years old. Kazan Pedagogical Journal. No. 6 (137). 